\title{
Microsatellite instability and its correlation with clinicopa- thological features in a series of thyroid tumors prevalent in iodine deficient areas
}

\author{
Minal Vaish ${ }^{1}$, Anjali Mishra ${ }^{2}$ \\ Manish Kaushal ${ }^{2}$, Saroj K Mishra ${ }^{2}$ \\ and Balraj Mittal ${ }^{1,3}$ \\ ${ }^{1}$ Department of Genetics \\ ${ }^{2}$ Endocrine Surgery \\ Sanjay Gandhi Post Graduate Institute of Medical Sciences \\ Rai Bariely Road \\ Lucknow-226014, U.P., India \\ ${ }^{3}$ Corresponding author: Tel, 91-522-2668700 (ex)2322; \\ Fax, 91-522-2668017; E-mail, balraj@sgpgi.ac.in
}

Accepted 3 February 2004

Abbreviations: AJCC, American Joint Committee on Cancer; AMES, Age, distant metastases, extra thyroidal invasion, tumor size; BA, Biallelic alteration; FNABC, Fine needle aspiration biopsy cytology; FTC, Follicular thyroid carcinoma; IDAs, lodine deficient areas; ISAs, lodine sufficient areas; LOH, loss of heterozygosity; MNG, Multinodular goiter; MSI-L, MSI-Low; MSI-H, MSI-High; MSI/MIN, Microsatellite instability; MSS, Microsatellite stable; MTC, Medullary thyroid carcinoma; PCR, Polymerase chain reaction; PDTC, Poorly differentiated thyroid carcinoma; PTC, Papillary thyroid carcinoma; RER+, Replication error positive; UI, Urinary lodine

\begin{abstract}
Thyroid tumors display diverse spectrum of histopathological groups with geographic variation in its prevalence. Influence of iodine deficiency (a major causative factor) in its etiology, prevalence, or aggressiveness is debatable which reflects the existence of various genetic events in pathogenesis. The present study was undertaken to study the role of Microsatellite instability (MSI) or $\mathrm{LOH}$ (loss of heterozygosity), an indicator of defective mismatch repair system as a genetic change and to explore it as a prognostic marker in thyroid tumors. Tumor tissues from total thyroidectomy surgical specimens and blood (matched control) of 36 patients from iodine deficient areas (10 benign; 26 malignant) were obtained after their consent. Urinary iodine analysis was done by alkali ash method for which $10 \mathrm{ml}$ of urine was collected from 18 patients before surgery. Genomic DNA,
\end{abstract}

isolated from tumor tissue and blood was amplified by polymerase chain reaction (PCR) using mono and dinucleotide markers - BAT-26, BAT-40, TGF(RII, IGFIIR, hMSH3, BAX, D2S123, D9S283, D9S851 and D18S58. PCR products were analysed on $8 \%$ denaturing polyacrylamide gel followed by autoradiography. Of total, $66.6 \%$ of tumors $[70 \%$ (7/10) benign and $65.4 \%$ malignant cases (17/26)] showed MSI/LOH. Strong association of MSI/LOH with low iodine $(P=0.01)$ and with AMES risk groups i.e. age $(P=0.02)$, tumor size $(P=0.04)$ and metastases $(P=0.002)$ in thyroid tumors was observed. This may help in predicting the biological behaviour and strengthening the hypothesis that iodine deficiency has influence on MSI in thyroid tumors. Our results further substantiate the risk group classification and help in deciding the treatment modality in particular patient.

Keywords: lodine deficiency; Microsatellite markers; Risk group; Thyroid cancer

\section{Introduction}

Thyroid tumors are the most frequent neoplasms of the endocrine system. The present therapy is based on patient age, tumor size and histology that decide the risk potential (Goretzki et al., 1998). Though total thyroidectomy is recommended for all cases of differentiated thyroid carcinoma as a primary treatment, sometimes hemithyroidectomy in low risk patients is advocated (Gemsenjager et al., 1997). Geographic variation in the biological behaviour has been observed. In the endemic iodine deficient region, total thyroidectomy has been recommended by some investigators irrespective of risk group even in occult papillary thyroid cancer (Mishra et al., 2002a). This discrepancy in deciding the tumor behaviour and treatment protocols encourages the development of molecular prognostic markers which could provide possible answer in predicting the biological behaviour of thyroid tumors.

Diverse spectrum of tumors originating from thyroid follicular cell, exhibiting different biological behaviour is suggestive of alternative pathways of thyroid tumorigenesis (Farid et al., 1994). Faulty mismatch repair mechanism can be demonstrated by frequent 
somatic variation in the size of microsatellites called as microsatellite instability (MSI/ MIN) or loss of one allele known as loss of heterozygosity ( $\mathrm{LOH}$ ) in tumor DNA as compared with matching normal DNA (Ionov et al., 1993). It reflects a defect in DNA replication or repair in damaged DNA and therefore, also known as replication error positive (RER+) phenotype which persists throughout the lifetime of the tumor (Shibata et al., 1994).

Lower incidence of $\mathrm{MSI}$ in thyroid tumors is because mutations in mismatch repair genes have been identified only in minority of cases. In a series of nine cases no incidence of $\mathrm{MSI}$ was reported (Vermiglio et al., 1995) whereas limited incidence of MSI was observed in larger series of tumors (Soares et al., 1997). PCR based MSI analysis in thyroid tumors may allow identification of MMR status that can be further correlated with the risk groups that could help in deciding the extent of treatment in a particular patient. This study was undertaken to evaluate the status of $\mathrm{MSI} / \mathrm{LOH}$ in thyroid tumors using mono and dinucleotide microsatellite markers situated on various chromosomes and to identify its association with high and low risk groups thereby exploring its role as a prognostic marker in thyroid cancer.

lodine deficiency has been considered as a major factor in the higher incidence of follicular and anaplastic carcinoma in iodine deficient areas (IDAs) as compared to papillary thyroid carcinoma in iodine sufficient areas (ISAs) with controversies (Franceschi, 1998). The relationship of endemic goiter and thyroid carcinoma including, prevalence, distribution and aggressiveness is debatable. Although iodine deficiency has been studied as a major environmental factor that leads to thyroid tumorigenesis, the wide variation in response to iodine deficiency as measured by the prevalence of follicular and papillary carcinoma is also reported. Since the role of iodine deficiency on MSI/ $\mathrm{LOH}$, which reflects the defective MMR system, is not known, the present work was undertaken to study the influence of iodine deficiency on the response to DNA damage in thyroid tumors.

\section{Materials and Methods}

\section{Patient selection}

Clinical assessment of thyroid tumors was based on history of goiter. Fine needle aspiration biopsy cytology (FNABC) was performed for the diagnosis of thyroid tumors. Total thyroidectomy was proposed in all cases. Following total thyroidectomy whole body radioiodine scan was performed to detect metastases. After radioactive iodine ablation of residual and metastatic deposits thyroid suppression therapy was ins- tituted in all cases. All available clinical data was combined with pathologic study of surgically resected specimen for assessment of risk group. Tissue specimens of thirty six cases of sporadic thyroid tumors from unrelated patients hailing from lodine deficient regions were obtained from total thyroidectomy surgical specimens during the last two years at endocrine surgery operation theatre in our institute. From the same group of patients, $5 \mathrm{ml}$ of blood was taken in $200 \mu \mathrm{l}$ of $0.5 \mathrm{M}$ EDTA as control after taking their consent. The samples were immediately snap frozen in liquid nitrogen and stored at $-70^{\circ} \mathrm{C}$ till DNA extraction. The present study material comprised of histopathology of series of thyroid tumors such as single case of multinodular goiter with oncocytic carcinoma, adenomatous goiter, Hashimoto thyroiditis, oncocytic adenoma, microfollicular adenoma, two cases of multinodular goiter (MNG), poorly differentiated thyroid carcinoma (PDTC), three cases of diffuse hyperplasia and medullary thyroid carcinoma (MTC), nine cases of follicular thyroid carcinoma (FTC) and twelve cases of papillary thyroid carcinoma (PTC). A total of ten benign and twenty-six malignant cases were taken for the study. Thyroid tumors were diagnosed, classified and staged according to American Joint Committee on Cancer (AJCC) criteria (Beahrs et al., 1988). The clinicopathological features of 36 cases taken for the present study are demonstrated in Table 1.

For analysis of urinary iodine, $10 \mathrm{ml}$ of urine of eighteen patients out of 36 could be collected before surgery. The subset (18 patients) included six cases of PTC, four cases of FTC, two cases of PDTC and three cases of MTC and one case of Hashimoto's thyroiditis, oncocytic adenoma and multinodular goiter with oncocytic carcinoma.

\section{DNA extraction from blood and tissue specimen}

DNA was isolated from tumor tissue as well as blood using phenol-chloroform extraction method (Blin and Stafford, 1976).

\section{Microsatellite analysis}

Table 2 shows characteristics of six mono - and four dinucleotide microsatellite markers, which were studied to examine $\mathrm{MSI} / \mathrm{LOH}$ in thyroid tumors. The primer sequences for markers were searched from human genomic database. Polymerase Chain Reaction (PCR) amplification of DNA was done with primer pairs of concentration of $6 \mathrm{pmol}, 200 \mu \mathrm{M}$ dNTPs, $10 \mathrm{mM}$ Tris - $\mathrm{Cl}(\mathrm{pH}$ 8.3), $50 \mathrm{mM} \mathrm{KCl}, 1.5 \mathrm{mM} \mathrm{MgCl}, 0.25 \mathrm{U}$ of Taq polymerase (MSI, Fermentas), $100 \mathrm{ng}$ DNA and $2 \mu \mathrm{Ci}\left[\alpha-{ }^{32} \mathrm{P}\right] \mathrm{dCTP}$ (specific activity: 4,000 $\mathrm{Ci} / \mathrm{mmol}$ ) (BRIT, India) in a total volume of $25 \mu \mathrm{l}$. PCR conditions involved an initial denaturation at $95^{\circ} \mathrm{C}$ for $3 \mathrm{~min}$ followed by 30 cycles $\left(95^{\circ} \mathrm{C}\right.$ for $1 \mathrm{~min}$, 
$50^{\circ} \mathrm{C}$ to $60^{\circ} \mathrm{C}$ for $2 \mathrm{~min}$ and $72^{\circ} \mathrm{C}$ for $3 \mathrm{~min}$ ) and a final extension at $72^{\circ} \mathrm{C}$ for $8 \mathrm{~min}$. PCR products were mixed with equal volume of formamide loading dye (95\% formamide, $20 \mathrm{mM}$ EDTA, 0.05\% bromophenol blue, $0.05 \%$ Xylene cyanol), denatured for $3 \mathrm{~min}$ at $95^{\circ} \mathrm{C}$ and loaded onto an $8 \%$ polyacrylamide gel containing $7 \mathrm{M}$ urea. Gels were run at $55 \mathrm{~W}$ for 2 hours, transferred onto a Whatman sheet, dried under vacuum and autoradiography was done.

The tumor was called unstable if its PCR product had altered band pattern when compared to alleles in corresponding matched blood DNA (Zhou et al., 1997). The changes could be mono-allelic (insertion/ deletion), bi-allelic (biallelic alteration) and $\mathrm{LOH}$. MSI/ $\mathrm{LOH}$ were categorized as MSI-High (MSI-H), if change was observed at or more than $30 \%$ loci studied and MSI-Low (MSI-L) if it was observed at less than $30 \%$ of loci examined.

\section{Determination of Urinary lodine}

Urinary iodine was analyzed using alkali ash method (Karmarkar et al., 1986) with slight modifications. Urine sample was mixed to evenly suspend any sediment. Appropriate dilutions were prepared from a stock iodine solution (168.5 mg in $100 \mathrm{ml}$ of water) to give standards covering a range of $0-20 \mathrm{mg} / \mathrm{L}$ and volume was made up to $100 \mu \mathrm{l}$. To $100 \mu$ of urine sample, $300 \mu$ of potassium carbonate $(0.00063 \mathrm{~N})$ was added to each tube and mixed. After drying the samples at $80^{\circ} \mathrm{C}$ to $100^{\circ} \mathrm{C}$ for overnight, ashing was done by placing the samples into the muffle furnace at $600^{\circ} \mathrm{C}$ for six $\mathrm{h}$. After cooling, $3 \mathrm{ml}$ of sodium meta-arsenite $(0.035 \mathrm{~N})$ was added and centrifuged at $2,500 \mathrm{~g}$ for seven min. The supernant was incubated for five $\min$ at $56^{\circ} \mathrm{C}$ in a water bath followed by addition of $3 \mathrm{ml}$ of ceric ammonium sulfate $(0.005 \mathrm{~N})$ at $30 \mathrm{~s}$ intervals to each tube, mixed, and replaced in a water bath. Twenty min after the addition of the ceric ammonium sulfate, transmittance was read at $420 \mathrm{m \mu}$ in a spectrophotometer against water (blank) to calculate the concentration $(\mathrm{mg} / \mathrm{L})$ of urinary iodine.

\section{Statistical analysis}

Non-parametric tests including Fisher's exact probability test (two tailed) and $2 \times 2$ contingency table with Yates correction were applied to study the association between MSI/LOH and clinicopathological features in thyroid tumors. Karl Pearson's correlation coefficient test was used to examine the correlation of iodine deficiency with MSI/LOH.

\section{Results}

\section{Microsatellite analysis}

Thirty-six cases paired to their controls (blood), were examined for $\mathrm{MSI}$ at six mononucleotide and four

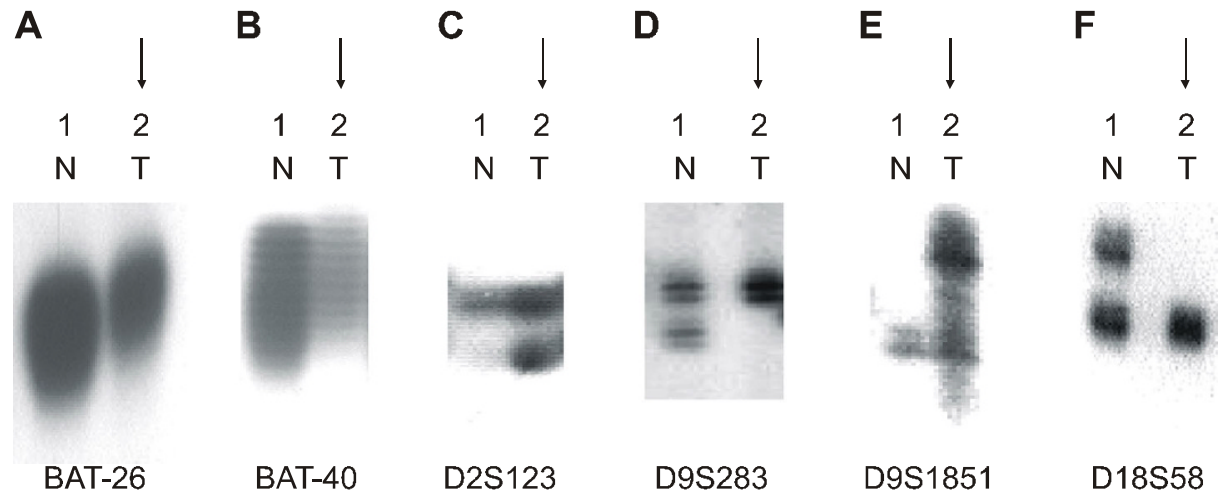

A

$\begin{array}{llllllll}12 & 3 & 4 & 5 & 6 & 7 & 8\end{array}$

N T N T N T N T

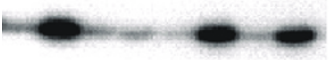

BAX
B $\begin{array}{llll}1 & 2 & 3 & 4\end{array}$ $\mathrm{N} \quad \mathrm{T} \quad \mathrm{N} \quad \mathrm{T}$

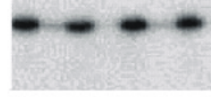

hMSH3
C $\begin{array}{llll}1 & 2 & 3 & 4 \\ N & T & N & T\end{array}$

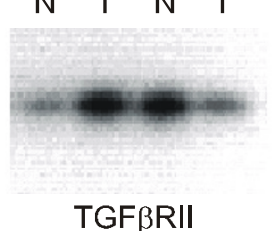

D $\begin{array}{llll}1 & 2 & 3 & 4\end{array}$ $\begin{array}{llll}\mathrm{N} & \mathrm{T} & \mathrm{N} & \mathrm{T}\end{array}$

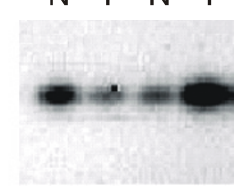

IGFIIR
Figure 1. Abnormal electrophoretic migration at mono and di- nucleotide repetitive regions, identified in tumor DNA (T) when compared to blood DNA (control, N). (A) BAT26: Insertion; (B) BAT- 40: Insertion; (C) D2S123: Deletion; (D) D9S283: Loss of Heterozygosity; (E) D9S1851: Insertion; (F) D18S58: Loss of eterozygosity. Changes are indicated by an arrow.
Figure 2. No change in allelic pattern at mononucleotide microsatellite markers observed in tumor DNA (T) as compared to germline DNA (N). (A) BAX: (lanes 1-8); (B) hMSH3: (lanes 1-4); (C) TGF (RII: (lanes 1-4); (D) IGFIIR: (lanes 14). 
Table 1. Clinicopathological features of thyroid tumors.

\begin{tabular}{|c|c|c|c|c|}
\hline $\begin{array}{c}\text { Case } \\
\text { no. }\end{array}$ & $\begin{array}{l}\text { Gender* } \\
\text { /Aqe** }\end{array}$ & Diagnosis & $\begin{array}{l}\text { Tu } \\
\text { size }\end{array}$ & $\begin{array}{l}\text { Tumor } \\
\text { ize }(\mathrm{cm})\end{array}$ \\
\hline 1 & $\mathrm{~F} / 24$ & Diffuse hyperplasia & na & na \\
\hline 2 & $\mathrm{~F} / 46$ & PTC & T3NoMx & 5 \\
\hline 3 & $F / 66$ & FTC & T3NoM1 & 6 \\
\hline 4 & $\mathrm{~F} / 46$ & FTC & T4bNoM1 & 5 \\
\hline 5 & $\mathrm{~F} / 44$ & PTC & T3N1Mx & 8 \\
\hline 6 & $M / 31$ & Diffuse hyperplasia & na & na \\
\hline 7 & $\mathrm{~F} / 44$ & MNG & na & na \\
\hline 8 & $M / 38$ & Microfollicular adenoma & na & na \\
\hline 9 & $\mathrm{~F} / 50$ & Diffuse hyperplasia & na & na \\
\hline 10 & $\mathrm{~F} / 60$ & Adenomatous goitre & na & na \\
\hline 11 & $\mathrm{~F} / 50$ & PDTC & T4NoM1 & $11 \times 9$ \\
\hline 12 & $\mathrm{~F} / 19$ & MNG & na & $10 \times 8$ \\
\hline 13 & $\mathrm{M} / 40$ & PTC & T4N1bM1 & 6 \\
\hline 14 & $M / 65$ & MTC & T4bNoMx & $25 \times 20$ \\
\hline 15 & $\mathrm{M} / 36$ & MTC & T3N1Mx & 2 \\
\hline 16 & $\mathrm{~F} / 56$ & FTC & T3NoM1 & 10 \\
\hline 17 & $F / 68$ & $\begin{array}{l}\text { Hashimoto's thyroiditis } \\
\text { MNG with oncocytic }\end{array}$ & na & 8 \\
\hline 18 & $F / 60$ & Carcinoma & na & na \\
\hline 19 & $\mathrm{M} / 67$ & FTC & T4NoM1 & 8 \\
\hline 20 & $\mathrm{~F} / 27$ & PTC & TxN1M1 & 14.5 \\
\hline 21 & $\mathrm{~F} / 55$ & FTC & T4NoM1 & 10 \\
\hline 22 & $\mathrm{~F} / 43$ & PTC & T3N1Mx & 6 \\
\hline 23 & $\mathrm{~F} / 51$ & Oncocytic adenoma & na & 7 \\
\hline 24 & $M / 55$ & MTC & T3N1Mx & 7 \\
\hline 25 & $M / 55$ & FTC & T4NoMx & 7 \\
\hline 26 & $\mathrm{~F} / 37$ & PTC & T2NoMx & 4.5 \\
\hline 27 & $\mathrm{~F} / 65$ & FTC & T2NoM1 & 4 \\
\hline 28 & $F / 33$ & PTC & T2NoMx & 4 \\
\hline 29 & $\mathrm{~F} / 48$ & PDTC & T4N1Mo & 10 \\
\hline 30 & $\mathrm{M} / 62$ & PTC & TxN1Mx & $>5$ \\
\hline 31 & $F / 26$ & PTC & $\mathrm{T} 2 \mathrm{bN} 1 \mathrm{bMx}$ & 3.5 \\
\hline 32 & $\mathrm{M} / 27$ & PTC & T4N1Mo & 4 \\
\hline 33 & $\mathrm{M} / 44$ & FTC & T2NoMx & 6 \\
\hline 34 & $M / 57$ & PTC & T3N1Mo & 7 \\
\hline 35 & $M / 38$ & FTC & TxN1Mo & $2 \times 1.5$ \\
\hline 36 & $M / 38$ & PTC & T4NoM1 & $<5$ \\
\hline
\end{tabular}

${ }^{*} \mathrm{M}=$ Male; $\mathrm{F}=$ Female; ${ }^{* *}$ Age in years; TNM (Tumor Node Metastases) staging according to AJCC criteria (Beahrs et al., 1988); PTC (Papillary thyroid carcinoma); FTC (Follicular thyroid carcinoma); PDTC (Poor differentiated thyroid carcinoma); MTC (Medullary thyroid carcinoma) and MNG (Multinodular goiter); na = not available.
Table 2. Characteristic features of microsatellite markers examined in thyroid tumors or tumor like lesions.

\begin{tabular}{|c|c|c|c|}
\hline $\begin{array}{c}\text { Name of } \\
\text { marker }\end{array}$ & $\begin{array}{l}\text { Repeat } \\
\text { pattern }\end{array}$ & $\begin{array}{l}\text { Chromosomal } \\
\text { location }\end{array}$ & $\begin{array}{l}\sim P C R \text { produc } \\
\text { size }\end{array}$ \\
\hline BAT 26 & $(A)_{26}$ & $\begin{array}{c}5^{\text {th }} \text { intron of } \\
\text { hMSH2, } 2 p\end{array}$ & $117-130 \mathrm{bp}$ \\
\hline BAT 40 & $(A)_{40}$ & $\begin{array}{l}2^{\text {nd }} \text { intron of } \beta \\
\text { hydroxy steroid } \\
\text { dehydrogenase }\end{array}$ & $94-112$ bp \\
\hline BAX $(38-41)$ & $(G)_{8}$ & $19 q 13.3-q 13.4$ & $94 \mathrm{bp}$ \\
\hline $\begin{array}{l}\text { TGF } \beta \text { RII } \\
(665-737)\end{array}$ & $(A)_{10}$ & $3 p 22$ & $73 \mathrm{bp}$ \\
\hline $\begin{array}{l}\text { IGFIIR } \\
(4030-4140)\end{array}$ & $(G)_{8}$ & $6 q 26-27$ & 110 bp \\
\hline $\begin{array}{l}\text { hMSH3 } \\
(381-383)\end{array}$ & $(A)_{8}$ & $5 q$ & $150 \mathrm{bp}$ \\
\hline D2S123 & $\begin{array}{c}(\mathrm{CA})_{13} \mathrm{TA} \\
(\mathrm{CA})_{15}(\mathrm{~T} / \mathrm{GA})_{7}\end{array}$ & $2 p 16$ & $197-227 b p$ \\
\hline D9S283 & $(C A) n$ & $9 q 13-q 22$ & $178-203$ bp \\
\hline D9S1851 & $(\mathrm{CA}) \mathrm{n}$ & $9 q 22.3$ & $143-159 \mathrm{bp}$ \\
\hline D18S58 & $(\mathrm{GC})_{5} \mathrm{GA}(\mathrm{CA})_{17}$ & $18 q 22.3$ & $144-160 \mathrm{bp}$ \\
\hline
\end{tabular}

dinucleotide microsatellite loci. Of total, $66.6 \%$ tumors showed $\mathrm{MSI} / \mathrm{LOH}$, which includes $70 \%$ (7/10) benign and $65.4 \%$ malignant cases $(17 / 26)$ as evident by electrophoretic mobility shifts in tumor DNA as compared to blood DNA. These changes were monitored as mono allelic (deletion, insertion), biallelic allelic [biallelic alteration (BA)] and LOH (Figure 1). However, no change has been observed at TGF $\beta R I I$, IGFIIR, $\mathrm{BAX}$ and hMSH3 loci in tumor DNA (Figure 2).

Out of the total benign tumors analyzed for MSI/ $\mathrm{LOH}$, six cases were unstable at BAT - 40, while a single case of diffuse hyperplasia was unstable at BAT - 26 and D9S1851. Rest of them were microsatellite stable (MSS).

Of malignant cases, PTC (66.6\%) (8/12) and FTC $(77.7 \%)(7 / 9)$ exhibited instability at BAT - 26, BAT 40, D2S123, D9S283, D9S1851 and D18S58. Out of the two cases of PDTC examined, single case was unstable at D9S283 and another one was observed as stable. Chromosomes 2, 9 and 18 exhibited allelic changes at D2S123, D9S283 and D18S58 respectively in a single case of FTC. Two out of three $(66.6 \%)$ MTC exhibited alteration at BAT - 40 and D2S123 while the remaining one did not harbor any change. 


\section{Microsatellite alterations and risk assessment}

Twenty-six cases of malignant thyroid tumors were evaluated for their association between the risk groups by studying independent variables like patient age, tumor size and metastases vs instability or stability at microsatellites. The risk assessment was done according to AMES (Age, distant metastases, extra thyroidal invasion, tumor size) risk classification (Kebebew and Clark, 2001). Men of age less than 40 years and women less than 50 years are at low risk if they do not have distant metastases. Older patients with intra-thyroidal tumor with minor capsular invasion, primary tumor of size less than $5 \mathrm{~cm}$ and no distant metastases are at low risk potential. MSI/ $\mathrm{LOH}$ positive malignant tumors were found to be present in $81.2 \%(13 / 16), 83.37 \%(15 / 18)$ and $65 \%$ $(13 / 20)$ of high-risk patients when compared with age, tumor size and metastases respectively. However, MSI/LOH was observed in $40 \%(4 / 10) ; 37.5 \%(3 / 8)$

Table 3. Association of microsatellite changes with risk of developing thyroid carcinoma by studying independent variables.

\begin{tabular}{|c|c|c|c|c|c|}
\hline \multirow{2}{*}{ Case no. } & \multicolumn{5}{|c|}{$\mathrm{MSI} / \mathrm{LOH}$ and risk groups } \\
\hline & Age & $\begin{array}{l}\text { Tumor } \\
\text { size }\end{array}$ & Metastases & & $\begin{array}{l}\text { MSI-L/ } \\
\text { MSI-H }\end{array}$ \\
\hline 2 & Low & High & Low & $+v e$ & (MSI-L) \\
\hline 3 & High & High & High & $+v e$ & (MSI-L) \\
\hline 4 & High & High & High & $+v e$ & (MSI-L) \\
\hline 5 & Low & High & High & & -ve \\
\hline 11 & High & High & High & & $-v e$ \\
\hline 13 & High & High & High & $+v e$ & (MSI-L) \\
\hline 14 & High & High & Low & $+v e$ & (MSI-L) \\
\hline 15 & Low & Low & High & & $-v e$ \\
\hline 16 & High & High & High & $+v e$ & (MSI-H) \\
\hline 19 & High & High & High & $+\mathrm{ve}$ & (MSI-L) \\
\hline 20 & High & High & High & $+v e$ & (MSI-H) \\
\hline 21 & High & High & High & $+v e$ & (MSI-H) \\
\hline 22 & Low & High & High & & -ve \\
\hline 24 & High & High & High & $+\mathrm{ve}$ & (MSI-L) \\
\hline 25 & Low & High & Low & $+v e$ & (MSI-H) \\
\hline 26 & Low & Low & Low & $+v e$ & (MSI-H) \\
\hline 27 & High & Low & High & & -ve \\
\hline 28 & Low & Low & Low & & -ve \\
\hline 29 & Low & High & High & $+v e$ & (MSI-L) \\
\hline 30 & High & High & High & $+v e$ & (MSI-L) \\
\hline 31 & Low & Low & High & & -ve \\
\hline 32 & Low & Low & High & $+v e$ & (MSI-L) \\
\hline 33 & High & High & Low & $+v e$ & (MSI-L) \\
\hline 34 & High & High & High & $+v e$ & (MSI-L) \\
\hline 35 & Low & Low & High & & -ve \\
\hline 36 & High & Low & High & $+v e$ & (MSI-H) \\
\hline
\end{tabular}

Age: Male $<40$ years; Female $<50$ years (Low risk). Tumor size: less than $5 \mathrm{~cm}$ (Low risk). Metastases (with nodal involvement): High risk (TNM classification on the basis of histopathology). MSI: -MSI-L (low); MSI-H (High); -ve (stable). and $83.3 \%(5 / 6)$ low risk patients (Table 3). Significant association was observed between $\mathrm{MSI} / \mathrm{LOH}$ and low risk groups $[P=0.02$ for age, $P=0.04$ for tumor size and $P=0.002$ for metastases using Fisher's exact probability test (two tailed)].

\section{MSI-L and MSI-H}

In the present study only one benign case presented with diffuse hyperplasia (10\%) (1/10) exhibited MSI-H. However, $33.3 \%$ cases of FTC (3/9) $25 \%$ cases of PTC (3/12) and no case of PDTC (0/2) manifested $\mathrm{MSI}-\mathrm{H}$. None of the MTC (0/3) studied showed MSI - H. MSI-L was found to be frequent in the low and

Table 4. Evaluation of MSI/LOH with different microsatellite markers and urinary iodine in thyroid tumors and tumor like lesions.

\begin{tabular}{|c|c|c|}
\hline Case no & $\begin{array}{l}\text { Microsatellite } \\
\text { changes }\end{array}$ & $\begin{array}{l}\text { Jrinary lodine } \\
(\mathrm{mg} / \mathrm{L})\end{array}$ \\
\hline 1 & ${ }^{*} \mathrm{High}$ (BAT-26, D9S1851) & na \\
\hline 2 & **Low $($ BAT-26) & 10.5 \\
\hline 3 & Low (D9S283) & $<1.25$ \\
\hline 4 & Low (BAT-26) & 11.25 \\
\hline 5 & ${ }^{* * *}$ MSS & $>20$ \\
\hline 6 & Low (BAT -40$)$ & na \\
\hline 7 & Low (BAT-40) & na \\
\hline 8 & MSS & na \\
\hline 9 & Low (BAT-40) & na \\
\hline 10 & MSS & na \\
\hline 11 & MSS & $<1.25$ \\
\hline 12 & Low (BAT-40) & na \\
\hline 13 & Low (BAT-40) & na \\
\hline 14 & Low (D2S123) & $<5.0$ \\
\hline 15 & MSS & $>20$ \\
\hline 16 & High (BAT-40, D18S58) & 10.5 \\
\hline 17 & Low $($ BAT-40) & 11 \\
\hline 18 & MSS & 5.75 \\
\hline 19 & Low $($ BAT-26) & $<1.25$ \\
\hline 20 & High (BAT-40, D9S283, D9S1851) & $<1.25$ \\
\hline 21 & High (D2S123, D9S1851) & na \\
\hline 22 & MSS & $<5.0$ \\
\hline 23 & Low (BAT-40) & $>20$ \\
\hline 24 & Low (BAT-40) & $>20$ \\
\hline 25 & High (D2S123, D9S283, D18S58) & na \\
\hline 26 & High (D2S123, D9S283) & na \\
\hline 27 & MSS & na \\
\hline 28 & MSS & 10 \\
\hline 29 & Low (D9S283) & 7.5 \\
\hline 30 & Low (BAT-40) & na \\
\hline 31 & MSS & na \\
\hline 32 & High (D9S283, D9S1851, D18S58) & $<1.25$ \\
\hline 33 & Low (D9S283) & na \\
\hline 34 & Low (D9S283) & na \\
\hline 35 & MSS & na \\
\hline 36 & High (BAT-40) & na \\
\hline
\end{tabular}

${ }^{*}$ MSI-High (MSI-H); **MSI-Iow (MSI-L); ${ }^{* * * M i c r o s a t e l l i t e ~ S t a b l e ~(M S S) ; ~}$ na $=$ not available. 
high-risk groups but a strong association of $\mathrm{MSI}-\mathrm{H}$ was seen in low risk group (tumor size) [Fisher's exact probability test (two tailed), $P=0.17$ for age; $P$ $=0.1$ for metastases and $P=0.002$ for tumor size].

\section{$\mathrm{MSI} / \mathrm{LOH}$ and tumor stage}

Clinical stages reflecting the behaviour of the tumors were studied with $\mathrm{MSI} / \mathrm{LOH}$. Fourteen out of eighteen malignant tumors $(78 \%)$ with clinical stage T3 or T4 demonstrated MSI (Fisher's exact probability test [two tailed], $P=0.006$ ). However, only $40 \%$ tumors with T2 stage showed $\mathrm{MSI} / \mathrm{LOH}$.

\section{Evaluation of Urinary lodine and its Association with $\mathrm{MSI} / \mathrm{LOH}$}

Urinary iodine (UI) values in $\mathrm{mg} / \mathrm{L}$ were calculated in $15 / 26$ thyroid carcinomas and $3 / 10$ benign tumors (Table 4). The range between $0-20 \mathrm{mg} / \mathrm{L}$ has been considered as low while normal value lies above 20 $\mathrm{mg} / \mathrm{L}$.

Out of the total twelve cases of carcinoma excluding MTC, examined for UI, eleven had low UI. Out of eleven, eight were microsatellite unstable and three were MSS $(72.3 \%$ vs $27.3 \%)$ [Pearson's correlation coefficient test $(P=0.01)]$.

Out of three cases of MTC, two showed MSI and each had low and normal UI value. However, the remaining case was MSS and had normal UI. Very weak association could be established between low $\mathrm{UI}$ and $\mathrm{MSI}(P=0.2)$ using $2 \mathrm{X} 2$ contingency table with Yates correction.

\section{Discussion}

Carcinoma of the thyroid is an infrequent tumor with geographic variation in its prevalence (Farid et al., 1994). Environmental factor like iodine deficiency plays a crucial role in promoting the development of thyroid carcinoma. Higher incidence of follicular and anaplastic carcinoma is seen in IDAs as compared to ISAs (Lawal et al., 2001). Higher incidence of metastases in IDAs is observed where the majority of cases had synchronous, symptomatic skeletal metastases (Mishra et al., 2002b). Diverse spectrum of tumors and tumor like lesions originating from thyroid follicular cell, exhibiting different biological behaviour is suggestive of alternative pathways of thyroid tumorigenesis (Farid et al., 1994). Occult thyroid cancers are rarely $(0.9 \%)$ present as distant metastases (Lind et al., 1996) and commonly regarded as being of no clinical relevance. Recently a study on patients (most of them hailed from IDAs) with differentiated thyroid cancers (4/156), who presented initially with distant metastases and no gross signs of thyroid dis- ease, described the aggressiveness of the tumors (Mishra et al., 2002a). This is in consistence with the existence of various genetic events influenced by the iodine deficiency, involved in predisposing to thyroid carcinoma originating from follicular cells, which provides useful model to study its molecular genetics and may provide a rationale approach in deciding clinical treatment.

Microsatellite instability/LOH, an indicator of faulty DNA mismatch repair system is believed to be associated with the genetic defects, including the activation or inactivation of specific genes and promote tumorigenesis.

Recently attention has been centered on PCR based analysis of $\mathrm{MSI} / \mathrm{LOH}$ in tumor tissues as compared to corresponding matched normal, has been proved to be helpful in understanding the genetic basis of thyroid tumorigenesis that allows the identification and characterization of number of molecular events underlying the multistep process of transformation of normal thyrocytes into differentiated thyroid adenomas to carcinomas to poorly differentiated carcinomas.

Up to now studies on the occurrence and role of $\mathrm{MSI} / \mathrm{LOH}$ in thyroid tumors are fragmentary. A study based on small series of cases and limited number of microsatellite markers examined could not show any evidence of MSI (Farid et al., 1994; Alves et al., 2000) whereas other reports have been suggestive of limited role of $\mathrm{MSI}$ in both benign and malignant tumors using the different set of microsatellite markers (Soares et al., 1997; Zhou et al., 1997; Tomita et al., 1999). In our present study, $66.6 \%$ of thyroid tumors exhibited $\mathrm{MSI} / \mathrm{LOH}$ on examining six mono and four dinucleotide microsatellite markers, including all the benign tumors. This present work is in continuation of the previous published work (Vaish et al., 2003) where all the ten benign tumors were analyzed for the presence of $\mathrm{MSI}$ at BAT-26, BAT-40, TGF(RII, IGFIIR, hMSH3 and BAX. The initial results encouraged examining the role of $\mathrm{MSI} / \mathrm{LOH}$ in malignant tumors as well with more number of markers to establish $\mathrm{MSI}$ as a prognostic marker.

The equivalent incidence of $\mathrm{MSI}(70 \%)$ in benign and $(65.4 \%)$ in malignant thyroid cancers supports the hypothesis that $\mathrm{MSI} / \mathrm{LOH}$, which causes genomic instability is responsible for thyroid tumorigenesis at the early stage as well. Higher incidence of MSI was observed using different panel of markers in malignant vs benign tumors (Stoler et al., 2002). Our present data is in concordance with the previous study using a different subset of markers (Soares et al., 1997). Another study described overall frequency of $21.5 \%$ in fifty-one thyroid tumors (Lazzereschi et al., 1999), which differs from ours. High frequency of $\mathrm{MSI}$ at BAT -40 and BAT - 26 in present study sug- 
gests that the biochemical defects governing the spectrum of $\mathrm{MSI}$ in thyroid and colorectal cancer share some similarity that contradicts the previous finding (Onda et al., 2001).

Relatively higher frequency of $\mathrm{MSI} / \mathrm{LOH}$ in FTC followed by PTC and PDTC in our study explains the impaired efficiency of DNA repair mechanisms that promotes carcinogenesis as well as contributes to tumor progression. All the mono-allelic, bi-allelic changes and $\mathrm{LOH}$ were observed in FTC and PTC at different microsatellites located on 2, 9 and 18 chromosomes in contrast to MTC. This study indicates different molecular mechanisms playing role in the pathogenesis of PTC or FTC and MTC however; the number of MTC cases is too low to draw such conclusion.

We report the presence of deletion as the most frequent microsatellite alteration. Deletion at chromosome 1, 2, 9 and 18 may hypothesize the presence of tumor suppressor gene flanking the respective markers. Absence of instability at TGF(RII, IGFIIR, BAX, hMSH3 and D2S123 loci rules out the possibility of any genetic defect at these loci.

According to AMES risk classification, the three independent risk factors viz. age, tumor size and metastases were studied with the MSI/LOH status. Association of $\mathrm{MSI} / \mathrm{LOH}$ with low risk group may help in further defining the treatment protocols where the conservative approach is followed. MSI - H was found to be frequently associated with high-risk group cases. This finding is contradictory to the previous one where no associations between MSI status, patient's age, gender and tumor size were observed (Lazzereschi et al., 1999).

We report higher prevalence of MSI-L in tumors behaving aggressively with advanced clinical stage (T3 or more). However, no significant association has been observed with $\mathrm{MSI}-\mathrm{H}$ and clinical stage.

Many studies from IDAs report a preponderance of advanced lesions at presentation, which as such contribute to poor prognosis (Sarda and Kapur, 1990). We see relatively higher number of FTC and PDTC compared to ISAs. Some reports suggest that iodine deficiency may act as promoter rather than carcinogens in rats (Ohshima and Ward, 1984). This indicates that iodine deficiency somehow alters the molecular pathway that further leads to tumorigenesis. Correlation of urinary iodine values in a subset of patients was carried out with MSI/LOH results. To our surprise, it was observed that all the patients, diagnosed with FTC, PTC or PDTC exhibiting MSI/LOH were found to have low urinary iodine value. To the best of our knowledge this is the first report of its kind. However, no relation between benign tumors and low urinary iodine could be established. lodine deficiency is involved in thyroid tumorigenesis, influ- encing its genotypic and phenotypic features (Tallini, 2001). Our observations may suggest that iodine deficiency influences MSI/LOH, an indicator of defective MMR functions in thyroid tumorigenesis. It may be possible that thyroid carcinoma arising from follicular cell in IDAs has unique ways to respond to DNA damage that should be substantiated by further studies.

These findings confer that MSI/LOH not only acts as an early event in thyroid tumorigenesis but also is involved in progression of thyroid carcinoma, thereby having a great impact on the biology of thyroid tumors. Higher prevalence of $\mathrm{MSI} / \mathrm{LOH}$ and its frequent association with advanced clinical stage could help in predicting biological behaviour of thyroid tumors. Examination of $\mathrm{MSI} / \mathrm{LOH}$ with a panel of microsatellite markers in clinical subjects may further substantiate risk group classification in thyroid carcinoma patients and thereby defining the treatment protocols in a particular patient.

\section{Acknowledgement}

One of the authors 'Minal Vaish' is thankful to Central Council of Scientific \& Industrial Research (CSIR), Govt. of India for providing research fellowship.

\section{References}

Alves C, Silva F, Gusmao L, Seruca R, Soares P, Reis RM, Amorim A. Extended structural variation of a pentanucleotide repeat in the GSTP1 gene: charecterisation in a normal population and in thyroid and gastric tumors. Eur $\mathrm{J}$ Hum Genet 2000;8:540-4

Blin N, Stafford DW. A general method for isolation of high molecular weight DNA from eukaryotes. Nuc Acids Res 1976;3:2303

Farid NR, Shi Y, Zou M. Molecular basis of thyroid cancer. Endocr Rev 1994;15:202-32

Franceschi S. lodine intake and thyroid carcinoma-a potential risk factor. Exp Clin Endocrinol Diabetes 1998;106:S38-44

Gemsenjager E, Heitz PU, Martina B. Selective treatment of differentiated thyroid carcinoma. World J Surg 1997;21: 546-51

Goretzki PE, Witte J, Dotzenrath C, Schulte K.M, Simon D, Roher HD. Geographical differences of thyroid carcinoma and basic molecular principles. Langenbecks Arch Chir Suppl Kongressbd 1998;115:200-2

Ionov $\mathrm{Y}$, Peinado MA, Malkhosyan S, Shibata D, Perucho M. Ubiquitous somatic mutations in simple repeated sequences reveal a new mechanism for colon carcinogenesis. Nature 1993;363:558-61

Karmarkar MG, Pandav CS, Krishnamachari KAVR. Principle and procedure for iodine estimation: A laboratory manual. Ind Council of Med Res 1986 
Kebebew E, Clark O. Papillary thyroid cancer. In Surgical Endocrinology (G.M. Doherty \& B. Skogseid eds), 2001; 59-73. Lippincott Williams \& Wilkins, Philadelphia, USA

Lawal O, Agbakwuru A, Olayinka OS, Adelusola, K. Thyroid malignancy in endemic nodular goiters: prevalence, pattern and treatment. Eur J Surg Oncol 2001;27:157-61

Lazzereschi D, Palmirotta R, Ranieri A, Ottini L, Veri MC, Cama A, Cetta F, Nardi F, Colletta G, Mariani-Costantini R. Microsatellite instability in thyroid tumors and tumor like-lesions. $\mathrm{Br} \mathrm{J}$ Cancer 1999;79:340-5

Lind JD, Chao TC, Weng HF, Huang HS, Ho YS. Clinical presentations and treatment for 74 thyroid carcinomas. Comparision with nonoccult carcinomas in Taiwan. Am J Clin Oncol 1996;19:504-8

Mishra A, Mishra SK, Das BK, Pradhan PK. Differentiated thyroid cancer presenting as distant metastases. Eur J Surg 2002a;168:305-9

Mishra A, Mishra SK, Agarwal A, Das BK, Agarwal, G. Metastatic differentiated thyroid carcinoma: Clinicopathological profile and outcome in an iodine deficient area. World J Surg 2002b;26:153-7

Ohshima M, Ward JM. Promotion of N-methyl-N-nitrosourea-induced thyroid tumors by iodine deficiency in $\mathrm{F} \mathrm{344/}$ $\mathrm{NCr}$ rats. J Natl Cancer Inst 1984;73:289-96

Onda M, Nakamura I, Suzuki S, Takenoshita S, Brogren $\mathrm{CH}$, Stampanoni S, Li D, Rampino N. Microsatellite instability in thyroid cancer: hot spots, clinicopathological implications, and prognostic significance. Clin Cancer Res 2001;7:3444-9

Sarda AK, Kapur MM. Thyroid carcinoma. A report of 206 cases from an area with endemic goiter. Acta Oncol 1990; 29:863-7
Shibata D, Peinado MA, lonov $\mathrm{Y}$, Malkhosyan S, Perucho M. Genomic instability in repeated sequences is an early somatic event in colorectal tumorigenesis that persists after transformation. Nat Genet 1994;6:273-81

Soares $P$, dos Santos NR, Seruca R, Lothe RA, SobrinhoSimoes $M$. Benign and malignant thyroid lesions show instability at microsatellite loci. Eur J Cancer 1997;33:293-6

Beahrs $\mathrm{OH}$, Henson DE, Hutter RVP, Myers MH. Staging of cancer at specific anatomic sites - Head \& Neck sites: Thyroid gland. In Manual for staging of cancer 1988;57-62. JB Lippincott, Philadelphia, USA

Stoler DL, Datta RV, Charles MA, Block AW, Brenner BM, Sieczka EM, Hicks WL Jr, Loree TR, Anderson GR. Genomic instability measurement in the diagnosis of thyroid neoplasms. Head Neck 2002;24:290-5

Tallini G. Molecular pathobiology of thyroid neoplasms. Endocr Pathol 2002;13:271-88

Tomita S, Muto Y, Kusano T, Toda T. Genetic alterations in human malignant tumor. Rinsho Byori 1999;47:20-6

Vaish M, Mishra SK, Mandhani A, Mittal RD, Mittal B. Assessment of microsatellite instability in bladder and thyroid malignancies. Teratogenesis, Carcinogenesis and Mutagenesis, 2003;(Suppl 1):255-65

Vermiglio F, Schlumberger M, Lazar V, Lefrere I, Bressac B. Absence of microsatellite instability in thyroid carcinomas. Eur J Cancer 1995;31A:128

Zhou XP, Hoang JM, Cottu P, Thomas G, Hamelin R. Allelic profiles of mononucleotide repeat microsatellites in control individuals and in colorectal tumors with and without replication errors. Oncogene 1997;15:1713-8 